\title{
LIDERANÇA GLOBALMENTE RESPONSÁVEL: A PERCEPÇÃO DOS EXECUTIVOS SOBRE AS PRÁTICAS NAS ORGANIZAÇÕES BRASILEIRAS
}

\author{
Luiz Gustavo Meneses Barreto \\ Mestre em Administração pela Pontifícia Universidade Católica de Minas Gerais - PUC Minas \\ lgmeneses@zoho.com \\ Antonio Carvalho Neto \\ Doutor em Administração pela Universidade Federal de Minas Gerais - UFMG \\ Professor do Programa de Pós-Graduação da PUC Minas \\ carvalhoneto@pucminas.br \\ Betania Tanure \\ Doutora em Administração pela Brunel University - Inglaterra \\ Professora do Programa de Pós-Graduação da PUC Minas \\ betaniatanure@pucminas.br
}

\begin{abstract}
RESUMO
O objetivo deste estudo é avaliar de que maneira executivos brasileiros percebem as práticas de Responsabilidade Social Empresarial (RSE) e se essas práticas apresentam semelhanças com as proposições de uma liderança globalmente responsável. A premissa teórica partiu da concepção de que o objetivo da RSE é ir além do que é prescrito pelas leis, de que as empresas têm um grande poder de transformação social e de que o líder organizacional desempenha papel fundamental nesse processo. Entretanto, essa capacidade do líder é, muitas vezes, mal gerida, o que pode comprometer o desempenho organizacional e de comunidades inteiras. O estudo qualitativo em questão é de casos múltiplos. Foram entrevistados dois consultores e treze executivos de nível tático de quinze empresas brasileiras de médio e grande porte, de variados setores da economia, além da análise de vários documentos empresariais. A pesquisa indicou que existe uma distância muito grande entre discurso e prática na maioria das empresas investigadas, além de um parco entendimento do que seriam práticas globalmente responsáveis, existindo até mesmo uma falta de interesse pelo assunto. As lideranças se mostram despreparadas em salientar valores éticos como centrais nas suas ações, em praticar ações em contexto global e em ampliar o propósito das organizações no sentido de valorizar o ser humano, a sociedade e o meio ambiente.
\end{abstract}

Palavras-chave: Liderança globalmente responsável; Responsabilidade social empresarial; Responsabilidade social empresarial com o público interno; Sustentabilidade.

\section{GLOBALLY RESPONSIBLE LEADERSHIP: THE PERCEPTION OF BUSINESS PRACTICES IN BRAZILIAN ORGANIZATIONS}

\begin{abstract}
The objective of this study is to examine how Brazilian executives perceive the practices of Corporate Social Responsibility (CSR) and how these practices have similarities to the proposals of a Globally Responsible Leadership. The theoretical premise was based on the notion that CSR is going beyond what is prescribed by law, that the companies have great power for social change, and that the organizational leader has a crucial role in this process. However, this ability is often poorly managed, which can jeopardize organizational performance and entire communities. This qualitative research study is a multiple case study. Data collection was done through interviews with two advisors and thirteen tactical level executives of fifteen medium and large Brazilian corporations, as well as through analysis of various business documents. The research indicates that there is too much distance between discourse and practice in most of the companies investigated. There also seems to be a meager understanding of practices that would be globally responsible and there is even a lack of interest in the subject. The leaders show themselves unprepared to emphasize ethical values as central in their actions or to take actions in the global context to expand the purpose of organizations to enhance the individual, society, and the environment.
\end{abstract}

Key words: Corporate social responsibility; Globally responsible leadership; Sustainability. 


\section{INTRODUÇÃO}

As empresas têm vivenciado, cada vez mais, um aumento de complexidade dos negócios e têm passado a atuar em um mundo caracterizado por rápidas e constantes transformações, onde se acentuam a interdependência entre os povos, as nações, os governos e, principalmente, nos negócios. Entretanto, a maioria das organizações tem se mostrado despreparadas para atuar, de maneira sustentável, em um ambiente de desigualdades, sejam elas sociais, econômicas, ou ambientais (EFMD, 2006; Unesco, 2005).

As empresas, privadas ou estatais e nos mais diversos ramos, estão entre as instituições de maior influência do mundo. As corporações cresceram de maneira a superar econômica e financeiramente muitos estados nacionais. Mas, ao contrário destes, carecem de mecanismos reguladores que as façam responder a um público maior. Seus líderes estão dotados, dessa forma, de um poder que é, por muitas vezes, ignorado e mal gerido. (EFMD, 2006; UNESCO, 2005; Hardjono; Klein, 2004).

Esse novo contexto de negócios internacionais requer uma definição das atividades e responsabilidades corporativas que ampliem o escopo das metas e necessidades organizacionais, colocando novas prioridades além da mera geração de lucros. O contexto contemporâneo necessita de uma empresa amplamente responsável, que seja capaz de desenvolver um progresso econômico e social de uma maneira global, responsável e sustentável. Pensando nisso, líderes e representantes de vinte e uma empresas, escolas de negócio e centros de liderança reuniram-se em 2004, em Bruxelas, Bélgica, na criação da Iniciativa para Lideranças Globalmente Responsáveis (Global Responsible Leadership Initiative).

A Liderança Globalmente Responsável procura promover o direito de expressão, a honestidade, integridade e o alcance das metas por meios honestos, bem como o tratamento digno e humano, criando valor econômico e social perene na cultura organizacional. Dessa forma, compreender em que estado se encontram os líderes organizacionais pode trazer benefícios para a empresa e para os mais diversos stakeholders.

Dessa forma, este estudo se propõe a responder as seguintes perguntas, como direcionadores de pesquisa: De que maneira, os executivos percebem as práticas de responsabilidade social em empresas brasileiras? E de que maneira essas práticas apresentam semelhanças com as proposições de uma liderança globalmente responsável, segundo o modelo de Quinn e D’Amato (2008)?

\section{REFERENCIAL TEÓRICO}

\subsection{O conceito de responsabilidade social}

Os primeiros conceitos de responsabilidade social empresarial surgiram no final do século XIX e predominaram nos EUA até a década de 1930, tendo estreita relação com o modelo econômico liberal de Adam Smith. A ideia predominante era de que as empresas deveriam buscar a maximização do lucro, a geração de novos empregos e pagar corretamente suas dívidas e impostos, exercendo assim sua função social (Tenório, 2004).

Já de 1930 a 1950, o movimento da responsabilidade social empresarial passou a ter mais ênfase com o crescente aumento das pressões dos trabalhadores. Mais uma vez, o conceito se ampliou, determinando que as empresas, e não somente os empresários, deveriam ser responsáveis (Tenório, 2004).

Na década de 1990, Carroll propôs um modelo piramidal de quatro dimensões, que abrange as responsabilidades econômicas, legais, éticas e filantrópicas que a empresa deve alcançar para além das obrigações legais. Esse modelo piramidal foi revisto mais recentemente por Schwartz e Carroll (2003), sendo composto por três esferas que possuem pontos de intercessão, sendo eles os domínios de responsabilidade: econômico, legal e ético. A categoria filantropia deixa de ser tratada de forma isolada e passa a ser parte integrante das esferas econômica e ou legal.

Outro modelo importante, no final da década de 1990, foi o de Elkington (1998), em que o autor propõe o conceito do Triple Bottom Line. Por meio dele, as organizações socialmente 
responsáveis devem orientar suas ações com todos os stakeholders em três dimensões: econômica, ambiental e social, sendo capaz de criar valor através delas.

Aglieri e Borinelli (2001) destacam que, ao longo das últimas décadas, três grandes visões sobre RSE têm se mostrado predominantes, a saber: responsabilidade social como obrigação social; a responsabilidade social como aprovação social; e responsabilidade social como abordagem sistêmica dos stakeholders. Entretanto, em cada um desses campos, multiplicaram-se as definições acerca do conceito de RES.

Ainda hoje existe pouco consenso acerca de um conceito exato de responsabilidade social e sobre qual deve ser o nível de comprometimento. É possível dizer que é um conceito ainda em formação, uma vez que possui muitas variáveis, entre elas: o destino ou o espaço para o qual devem ser dirigidas as ações de RSE, quais os elementos que deveria contemplar e em que momento tais ações devem ser aplicadas, sendo elas preventivas ou reativas (Tenório, 2004).

Melo Neto e Froes (2001) afirmam que existem pelo menos quatorze conceitos de responsabilidade social, o que, segundo Maak (2008), é um dos principais problemas nos estudos e na efetiva aplicação desses termos. Por ser extremamente polissêmico e não possuir conceitos claros e bem definidos pode ser adotado nos mais diversos contextos e intenções. Esse campo de dissensos, contradições e ambiguidades favorece o discurso dos que defendem um modelo de desenvolvimento hegemônico e de falsa inclusão.

Essa dissonância entre discurso e prática pode determinar, em última instância, o que é conhecido também como greenwash. Esse termo, normalmente, é utilizado para designar um procedimento de marketing que alguma organização pode usar para conferir à opinião pública uma imagem de que seu comportamento, seus produtos e seus serviços são ecologicamente responsáveis, enquanto na prática a organização demonstra um comportamento contrário aos interesses e bens sociais e ambientais (Bruno, 1992).

Maak (2008) afirma que o termo responsabilidade social deveria ter proposições mais inclusivas e integrativas, propondo, dessa forma, uma "Responsabilidade Corporativa NãoDividida". Esse termo procura redefinir a responsabilidade social empresarial em termos mais concisos, colocando as ações da empresa de uma maneira interligada e sistêmica, orientada, a todo o momento, por princípios éticos. Esta responsabilidade se verifica por meio dos 7Cs, a saber: I) comprometimento; II) conduta; III) conteúdo; IV) contexto; V) consistência; VI) coerência e; VII) continuidade (Maak, 2008).

O caminho de uma empresa na criação de uma efetiva responsabilidade social precisa de um exame cuidadoso de missão, visão, valores e crenças, capazes de motivar uma nova conduta na sociedade, atendendo também as demandas do público interno, criando um ambiente saudável que permita a satisfação de clientes, acionistas, parceiros e funcionários, por meio de medidas transparentes e incentivadoras (Szekely, Knirsch, 2005).

O conceito de responsabilidade social empresarial adotado neste trabalho procura o ponto de equilíbrio entre as três esferas do modelo de Schwartz e Carroll (2003) e do Triple Bottom Line de Elkington (1998), seguindo a corrente de responsabilidade social como abordagem sistêmica dos stakeholders, como explicitado por Aglieri e Borinelli (2001). O conceito adotado orienta-se pela construção de valores capazes de motivar uma mudança de conduta na organização e na sociedade (Szekely; Knirsch, 2005), em concordância com a "Responsabilidade Corporativa Não-Dividida", de Maak (2008).

\subsection{Os estudos acerca da liderança}

Os primeiros estudos sobre liderança surgiram no século XIX e buscavam identificar as características natas e os atributos de grandes personalidades que caracterizavam a figura de um líder. Essa corrente predominou até a metade do século XX e foi chamada de Teoria dos Traços (Seters; Field, 1990).

McGregor (1966), na década de 1950, apresentou as Teorias X e Y. A teoria X descreve um estilo de administração e fiscalização muito rígido e controlador, que considera que o salário é o 
único estímulo que o empregado pode ter. Já segundo a teoria Y, a liderança tem a capacidade de liberar os potenciais e a motivação dos empregados, uma vez que se baseia em medidas inovadoras e humanistas.

Já na década de 1960, Blake e Mouton (1989) apresentaram uma matriz composta por dois eixos fundamentais, que delineavam cinco tipos fundamentais de lideranças e gestão, fundamentadas na qualidade das decisões e resultados e na orientação para pessoas. Esse modelo ficou conhecido por Grid Gerencial.

Seguindo essa mesma corrente, emergiu a chamada Teoria Situacional (Graeff, 1983) que seguia o pressuposto de que a liderança tem caráter contingencial. Dessa forma, o líder e liderados são variáveis que devem ser estudados em um contexto específico, podendo, portanto, assumir várias configurações diferentes.

Entretanto, muitos dos resultados encontrados pelas três correntes acima mencionadas não se mostraram expressivos, o que gerou um movimento contrário à liderança, chamado de Antileadership, por Seters e Field (1990 apud Sant'anna et al, 2009) e demonstrava, segundo Pfeffer (1977), três problemas centrais, a saber: a dificuldade de definição de um conceito; a determinação de qual o seu real impacto do desempenho organizacional; os processos de seleção e sucessão de líderes utilizavam critérios pouco satisfatórios.

Reagindo a esse movimento, na década de 1980, emergiu uma corrente de pensamento que estudava a liderança enquanto fenômeno cultural. Schein (1992) afirma que líderes são os responsáveis pela criação da cultura organizacional.

Posteriormente, principalmente a partir dos trabalhos de Burns (1978) e Bass (1985 apud Sant'anna et al, 2009), emerge mais uma corrente, chamada de Liderança Transformacional. No caso dessa corrente, o líder procura satisfazer as necessidades de alto nível dos seus seguidores, tratando-os como pessoas únicas e singulares, cujos potenciais podem ser despertos e aproveitados. Procura estabelecer fortes e duradouros laços com elas, tratando-as como iguais e esse comportamento é considerado capaz de produzir mudanças nas atitudes, crenças e nos objetivos dos liderados.

Ainda na corrente da Liderança Transformacional, Maak (2008) propõe o surgimento da Liderança Responsável, corrente esta utilizada neste trabalho como orientadora da pesquisa. Sua única diferença consiste na explicitação de que a maior meta da liderança transformacional deve ser uma busca mútua de líderes empresariais e stakeholders para que metas de alto nível, centradas na visão de que os negócios desempenham importante papel na transformação social positiva, sejam alcançadas.

\subsection{As características de uma liderança responsável}

As principais diferenças existentes entre a liderança e o gerenciamento dizem respeito ao comportamento e o relacionamento. Um dos principais aspectos que definem o líder é a sua capacidade de reunir pessoas com diferentes interesses a perseguirem uma visão comum futura, minimizando o impacto das visões pessoais. Já o gerente prioriza estruturas e sistemas, mantendo o controle, exercendo a função de administrador com metas mais focadas no curto prazo. Uma empresa eficiente é aquela em que seus líderes apresentam características gerenciais e seus gestores características de liderança, afinal líderes sem uma gestão criam ilusões e gerentes sem liderança criam baixa eficácia e elevam a insegurança e a ansiedade (Bennis, 2002; Yukl, 2009).

A mudança da organização para um papel socialmente responsável recai sobre esse gerente com características de liderança. Esse não é um processo fácil, pois muitas são as barreiras que precisam ser superadas e cabe ao líder organizacional começar do topo um sistema de exemplos, incentivos e engajamento em todos os níveis (Szekely; Knirsch, 2005; Tanure; Evans; Pucik, 2006).

De acordo com Maak e Pless (2006), uma liderança responsável é a arte de construir relações boas e sustentáveis com todos os stakeholders. Sua tarefa central é criar uma rede de inclusão na qual o líder se coloca no mesmo nível de seus liderados e propicia igualdade de 
tratamento entre todos, exercendo uma liderança ética e baseada em valores. Neste contexto, às pessoas não cabe o papel de ovelhas e ao líder, o de pastor. Ele deve ser apenas um articulador dos diferentes tipos de pessoas, profissões e necessidades existentes. O líder é um facilitador do processo relacional entre seus stakeholders seguidores, sendo também responsável por uma melhor qualidade das relações, atuando de maneira a colocar os valores éticos como centrais em suas ações e inspirando a todos a seguirem valores comuns e de bem- estar coletivo.

Nesse contexto empresarial, as lideranças parecem estar despreparadas para lidar com os novos desafios globais e os diversos papéis a desempenhar. Dessa forma, existem quatro desafios principais para um líder responsável, sendo eles a capacidade de pensar e agir em contexto global, a ampliação do propósito das organizações, a colocação da ética como central a todas as ações e a reformulação da educação de executivos (Doh, Stumpf, 2005; Quinn, D’amato, 2008).

\subsection{O movimento da liderança globalmente responsável}

A fim de consolidar um termo que abrangesse todas as concepções acerca da responsabilidade social, em 2005, cerca de vinte e uma empresas de diversos ramos econômicos e do conhecimento, várias escolas de negócios e centros de educação de múltiplos países encontraram-se na Europa com o apoio do Global Pact e da EFMD. A reunião dessas empresas objetivou formalizar os estudos sobre os conceitos de uma liderança globalmente responsável. Utiliza-se o termo "global" porque o mundo tem se tornado cada vez mais interconectado e isso tem diminuído as fronteiras em todos os âmbitos, ressaltando os desafios neste novo contexto que as empresas têm atuado. "Responsável" porque a criação de um mundo melhor e mais justo requer dos líderes empresariais uma nova postura e engajamento, no qual procurem assumir consequências de seu comportamento nos âmbitos social, econômico e ambiental (Efmd, 2006; Unesco, 2005; Hardjono; Klein, 2004).

Dessa forma, não parece haver diferenças significativas entre os termos "liderança globalmente responsável" e "líder responsável". Assim, este trabalho adotará essas denominações como sinônimos de um mesmo construto, embora prefira a expressão "liderança globalmente responsável", por esta parecer denotar, exclusivamente pelo seu termo, uma abrangência maior em seus significados.

\subsection{A responsabilidade social nas empresas brasileiras}

As empresas brasileiras encontram-se em diversos estágios da implementação da responsabilidade social como prática organizacional. Entretanto, falta ao executivo desempenhar papel central na disseminação de práticas socialmente responsáveis e colocá-las como processo estratégico nos negócios. O pensamento de que as responsabilidades sobre as demandas sociais competiam exclusivamente ao governo, devendo ele ser o responsável por educação, saúde e segurança, prevalecia até poucas décadas atrás entre o empresariado brasileiro. Naquele cenário, cabia, portanto, às organizações, apenas a aceleração da economia (Carvalho Neto; Andrade, 2009).

Principalmente a partir da década de 1980, essa crença passou a ser largamente criticada e perdeu a força, pois embora exista um entendimento comum de que o enfrentamento da questão social é tarefa essencial do poder público e de que o investimento social privado não deve substituir a ação governamental, o Estado sozinho não é capaz de resolver todos os problemas sociais. Dessa forma, cabem às organizações, estas responsáveis por grande parte do funcionamento da economia, responsabilidades que vão além de gerar empregos, pagar impostos e zelar pela qualidade dos produtos ou serviços prestados (Carvalho Neto; Andrade, 2009).

Ainda nessa mesma década, começou a ocorrer, no Brasil, uma série de ampliações e consolidações de políticas públicas promovidas pela legislação federal que buscavam aumentar a participação das empresas nas demandas sociais e econômicas. Essa abertura a uma parceria público-privada consiste em um mecanismo de concessão pública que compreende que nem o estado, nem as organizações têm condições, sozinhos, de responder às demandas sociais. O intuito 
dessa medida é a desburocratização do setor público e sua atuação tem aumentado, tanto no Brasil, quanto no exterior (Carvalho Neto; Andrade, 2009).

Em 1998, um instituto de grande importância para a causa da Responsabilidade Social foi criado pelo empresário Oded Grajew, o Instituto Ethos. No ano de 2000, esse instituto criou os Indicadores Ethos que consistem em parâmetros que podem ser utilizados pela organização para avaliar o seu nível de comprometimento com as questões sociais, auxiliando o administrador a identificar pontos fortes e débeis das práticas empresariais (Tenório, 2004). Porém, um dos limitadores é que as informações são fornecidas unilateralmente pelas empresas. O ideal é que houvesse iniciativa semelhante ao IBGE para realização de um levantamento de indicadores de sustentabilidade ao longo de todo o país e com todas as organizações, padronizando e facilitando o monitoramento (Azevedo, 2006).

A empresa comprometida com os princípios do desenvolvimento sustentável deve se preocupar com a divulgação dos dados de qualidade sob a forma de relatórios. Nesse sentido, o chamado "marketing social" é uma maneira de promover o reconhecimento das organizações quanto as suas medidas de RSE. Entretanto, essa imagem deve ser uma consequência de uma mudança de atitude, não apenas um discurso "politicamente correto". A empresa que não encontra respaldo na prática poderá comprometer seriamente a sua imagem no longo prazo (Azevedo, 2006; Tenório, 2004).

Apesar do número significativo de empresas que afirmam já possuírem práticas de RSE, Carvalho Neto e Furtado (2007), bem como Molica, Carvalho Neto e Gonçalves (2008), mencionam, também, haver uma distância relativamente grande entre o discurso e a prática de RSE, tendo muitas empresas colocado em prática programas de redução de custos com corte de pessoal e flexibilização a qualquer custo.

Visto isso, cabe agora verificar o grau de preparo dos executivos brasileiros em relação a práticas globalmente responsáveis.

\section{METODOLOGIA}

Para investigar o problema proposto, que consiste avaliar a percepção e as práticas de executivos brasileiros acerca de uma liderança globalmente responsável, a estratégia de pesquisa qualitativa se apresenta como melhor alternativa. Bogdam e Birklen, apud Triviños (1987), indicam cinco características essenciais das pesquisas qualitativas e que sustentam a escolha dessa estratégia de pesquisa para a realização deste trabalho, a saber: a pesquisa qualitativa utiliza o ambiente natural como fonte dos dados e o pesquisador como instrumento-chave; a pesquisa qualitativa é descritiva, e a interpretação dos resultados surge como a totalidade de uma especulação que tem como base a percepção de um fenômeno em um contexto. Não é vazia, mas coerente, lógica e consistente; os pesquisadores qualitativos estão preocupados com o processo e não apenas com os resultados e o produto; os pesquisadores qualitativos tendem a analisar seus dados indutivamente; a compreensão do significado é principal preocupação na abordagem qualitativa.

Para compreender a ligação entre contexto e o fenômeno no problema investigado, optou-se pela utilização da técnica do estudo de caso. De acordo com Yin (2003, p. 32), o método de estudo de caso é uma "[...] pesquisa empírica que investiga um fenômeno contemporâneo dentro de um contexto real de vida, no qual as fronteiras entre fenômeno e o contexto não são claramente evidentes e no qual múltiplas fontes de evidências são usadas". Utilizou o estudo de casos múltiplos, de maneira a avaliar as diferentes visões e práticas dos executivos em diferentes organizações.

Para a escolha dos casos, foi feito, inicialmente, um levantamento pelo pesquisador entre os alunos dos Programas de Mestrado em Administração da Fundação Dom Cabral e da PUC-Minas, de maneira a identificar aqueles que eram executivos de empresas e estariam dispostos a responder a entrevista. Inicialmente, doze alunos desse grupo ofereceram-se para a pesquisa, entretanto, para 
se atingir uma saturação teórica, foi realizado outro contato posterior com os alunos na busca de novos voluntários, o que resultou mais três novos casos.

Após essa identificação, um primeiro contato foi realizado por telefone para o agendamento da entrevista. Nesse contato, foi identificado o porte da empresa e o setor de atuação. A classificação adotada para o porte de empresa seguiu o mesmo parâmetro adotado pelo Banco Nacional do Desenvolvimento (BNDES) e aplicável à indústria, comércio e serviços, conforme a Carta Circular $n^{\circ}$ 64/02, de 14 de outubro de 2002 do próprio banco. A Figura 1 ilustra os resultados encontrados para esse critério:

\begin{tabular}{|l|l|l|}
\hline ENTREVISTADO & PORTE DA EMPRESA & SETOR \\
\hline E1 & Médio & Consultoria \\
\hline E2 & Grande & Consultoria \\
\hline E3 & Grande & Ensino \\
\hline E4 & Grande & Ensino \\
\hline E5 & Médio & Energia \\
\hline E6 & Médio & Tecnologia da Informação \\
\hline E7 & Médio & Engenharia Industrial \\
\hline E8 & Médio & Extrativismo Mineral \\
\hline E9 & Grande & Tecnologia da Informação \\
\hline E10 & Grande & Tecnologia da Informação \\
\hline E11 & Grande & Telecomunicações \\
\hline E12 & Grande & Siderurgia \\
\hline E13 & Grande & Energia \\
\hline E14 & Grande & Energia \\
\hline E15 & Grande & Financeiro \\
\hline
\end{tabular}

Figura 1- Classificação das empresas entrevistadas quanto ao setor e porte Fonte: Dados das entrevistas

A coleta de dados desta entrevista se deu a partir da análise de documentos e de entrevista semiestruturada. A entrevista foi elaborada a partir do Global Responsible Leadership Assessment (GRLA), de Quinn e D'Amato (2008). Esse instrumento consiste de uma extensa survey que avalia separadamente crenças acerca da responsabilidade social, a qualidade das práticas existentes e a frequência com que são usadas, sendo, de acordo com o EFMD (2006) umas das mais completas ferramentas acerca do estudo das lideranças globalmente responsáveis disponíveis na atualidade. Para atender os fins das pesquisas, foram utilizadas seis das oito categorias existentes no questionário, a saber: Desenvolvimento de visão, estratégias e políticas; Suporte da alta gerência; Ações éticas; Engajamento ao longo das fronteiras; Operacionalização da RSE; e Accountabillity de performance.

As categorias "Comunicação" e "Delegação de Poder" foram agregadas às categorias "Operacionalização da RSE" e "Engajamento ao longo das fronteiras", respectivamente. Isso se deveu por dois fatores fundamentais, sendo eles o tempo disponível pelos executivos para a realização das entrevistas e a semelhança entre os grupos de perguntas.

$\mathrm{O}$ aspecto da duração foi pautado pela dificuldade de agendamento de entrevistas e pelo pouco tempo disponível pelos executivos para essa atividade. Nesse sentido, o tempo médio estimado foi de vinte minutos, o que conseguiu atender com sucesso a essas limitações.

Já o aspecto da semelhança dos grupos de perguntas procurou integrar alguns dos aspectos de uma categoria em outra, de maneira a reduzir o número de questões e conseguir respostas mais satisfatórias dos entrevistados.

As entrevistas foram realizadas por meio do software Skype e a gravação foi realizada por intermédio de um dispositivo de MP4. 
Foi realizada também análise de documentos como fonte de evidência. Yin (2003) afirma que esses tipos de dados: são estáveis e possibilitam inúmeras revisões; são discretos e não são resultado do próprio estudo de caso; são exatos, pois contêm nomes, referências e detalhes exatos de um evento; e possuem ampla cobertura ao longo do tempo, conseguindo cobrir muitos eventos ambientes distintos. Neste trabalho, foram utilizados documentos disponíveis em meio eletrônico nos sites das empresas investigadas, como relatórios anuais de sustentabilidade, demonstrativos contábeis, códigos de ética, entre outros. Utilizou-se também de reportagens oficiais, publicadas em jornais eletrônicos reconhecidos, para melhor compreender o contexto da organização na mídia, na sociedade e no mercado.

Inicialmente, as quinze entrevistas realizadas foram gravadas e transcritas, gerando mais de cinco horas de gravação. Partiu-se então para o processo de triangulação, que consiste em uma combinação de metodologias no estudo do mesmo fenômeno que fornece ao pesquisador múltiplos pontos de vista à pesquisa (Eisenhardt, 1989; Yin, 2003). No caso deste trabalho, a triangulação foi realizada com os documentos e reportagens sobre as organizações investigadas, fazendo-se, primeiramente, como sugere Eisenhardt (1989), uma análise intracasos e uma análise entrecasos.

\section{ANÁLISE DOS DADOS}

\subsection{Desenvolvimento de visão, estratégias e políticas}

O primeiro grupo de perguntas realizadas procurou investigar qual a importância da Responsabilidade Social Empresarial e Sustentabilidade para a organização dos entrevistados. Procurou investigar também de que maneira ela se encontra explícita no seu modelo de negócios por meio de princípios e políticas para guiar as pessoas.

Gestores de quatro empresas salientaram possuir também grande preocupação com seu público interno, ao contrário de outras sete empresas que não forneceram exemplos, em um primeiro momento, nesse sentido. A resposta do entrevistado número 7 exemplifica bem isso: "eu percebo ela mais focada para os funcionários. Em relação às políticas de RH pra manutenção dentro da empresa, para satisfação das famílias dos funcionários". Os entrevistados dessas quatro empresas afirmaram que não possuíam missões expressas nos modelos de negócios, mas que o tema estava presente na cultura. Isso contrasta com as respostas de um terço dos entrevistados que afirmaram possuir diretrizes bastante específicas de RSE em seus modelos.

Sobre a existência de políticas e princípios para guiar as pessoas, a resposta geral foi de desconhecimento, como podemos ver nesse exemplo: "deixe-me ver se eu sei te falar isso de cabeça. Ela tem uma preocupação muito grande com a ética... muito grande com o treinamento dos funcionários e tudo, agora de responsabilidade social na política da empresa eu não sei te falar" (entrevistado número 10).

Entrevistados de sete empresas sugerem com suas respostas que suas organizações estão em estágios iniciais, uma vez que seus exemplos trataram principalmente de obras sociais e ambientais, não contemplando questões mais elaboradas de RSE, como a construção de valores centrais nos modelos de negócio ou o atendimento ao público interno. A maior parte dos exemplos mencionados, além de revelar um estágio inicial de RSE, possui uma relevância relativamente pequena para o porte de sete empresas, todas entre as maiores empresas do mundo em seus respectivos setores.

A confusão sobre a relevância das práticas de RSE pode ser percebida com clareza também nas respostas de vários entrevistados, como o do exemplo a seguir: "você deveria usar a tecnologia para conseguir utilizar os recursos naturais de uma forma mais adequada" (E9). Para esse entrevistado, a organização procurou propiciar aos clientes a capacidade de utilização eficiente de recursos por meio da tecnologia, porém esse era apenas o serviço oferecido pela organização. Em que esses processos representariam uma verdadeira RSE e não apenas uma tentativa de apresentar um discurso de responsabilidade? 
Os entrevistados salientam de forma mais clara as dificuldades das empresas, por exemplo, ao afirmar que a responsabilidade social "é algo muito importante" (E10), mas que não se lembrava do nome de alguns programas de sua organização. As atividades reduziam-se à criação de um plano de negócios em instituições parceiras de negócio e mais uma vez aqui é possível questionar a relevância real do projeto em termos de RSE no médio e longo prazo. Outros entrevistados orbitaram em medidas que já são asseguradas pelas leis da Constituição Federal Brasileira e do Estatuto da Criança e do Adolescente.

Alguns outros gestores ressaltaram a existência de programas de formação de mão de obra de primeiro emprego. Esse programa, quando investigado nas publicações anuais de RSE das empresas, revela ser uma formação educacional de jovens junto a universidades para, talvez, posteriores estágios e contratação pela própria organização. Porém, até onde essa prática poderia ser considerada uma efetiva prática de responsabilidade social? Afinal, em certo ponto, parece que ambas as organizações apenas estão investindo em seu próprio benefício na formação de estagiários e funcionários. Não que ambas as partes não possam lucrar com o processo, mas nos casos em questão esses projetos constam como uma das principais medidas de RSE das organizações.

A predominância de uma visão incipiente de RSE parece concordar com as respostas de entrevistados consultores de empresas. De maneira geral eles, afirmaram que a responsabilidade social e sustentabilidade para as empresas com as quais trabalharam ou trabalham "têm importância, mas não têm efetividade" (E1). Possuem importância interna para a empresa e "importância de divulgação, mas não é um diferencial de negócio". Afirmam também que a explicitação em princípios e valores se encontra presente "toda vez que faz diferença para o cara ganhar negócio ou perder negócio" (E2), mas não em outra ocasião.

\subsection{Suporte da alta gerência}

O segundo grupo de questões envolveu essencialmente uma avaliação das práticas da liderança. O foco inicial abordou a importância da alta gerência nas práticas de RSE e Sustentabilidade na empresa, bem como a maneira que essa alta gerência provê os recursos e incentivos necessários para a realização desse processo em todos os níveis da organização.

De maneira geral, os entrevistados de todas as organizações ressaltaram a importância do líder como figura central no processo de promoção de práticas socialmente responsáveis. Eles disseram que, se "[...] não houver efetivo incentivo e patrocínio pela alta gerência a coisa não acontece", devendo as medidas de RSE "[...] ficarem sinalizadas de forma muito clara por parte da alta administração" (E14). Ou que o movimento pode "[...] até surgir na base, pelo modismo, mas a importância para o processo de difusão pela RSE na organização tem que ser no mínimo validado pela alta liderança” (E2).

Os líderes das organizações de médio porte aparentam possuir uma grande proximidade com seus funcionários para a promoção de práticas de RSE, principalmente no que diz respeito à construção de um significado coletivo, aumento dos níveis de motivação e comprometimento com a criação de valores sustentáveis e inclusivos.

O mesmo não pode ser encontrado nas entrevistas da maioria das organizações de grande porte. Em alguns momentos, como o da crise mundial, ocorreu, segundo mais da metade dos entrevistados, corte de pessoal como primeira medida preventiva. Esse comportamento é mencionado na literatura como um comportamento contraditório a esse discurso.

Sobre a relevância e o alcance das práticas de RSE, ou que possam ser consideradas como tal, ainda há muita dúvida e má interpretação. Como exemplo, uma das empresas que se limitava a colocar no patrimônio histórico da cidade "[...] uma iluminação de Natal lá, então ponto" (E12). As contribuições dessa e de outras organizações investigadas parecem ser muito pequenas frente a todo o potencial das organizações, muitas delas entre as dez maiores do mundo em seus respectivos setores. 


\subsection{Ações éticas}

O terceiro grupo de questões abordou de que maneira os líderes têm estimulado o diálogo e a transparência das práticas de RSE/Sustentabilidade ao longo de toda organização. Procurou saber também se ações éticas e socialmente responsáveis (que consideram aspectos sociais, ambientais e financeiros, além dos previstos por lei na sua aplicação) são tomadas, independentemente de qualquer outro aspecto.

Todos os entrevistados afirmaram categoricamente que a ética é fundamental e que suas empresas a praticam como fundamento básico do negócio. Porém, alguns entrevistados deixaram claro que a maioria das empresas "[...] falam que praticam o processo internamente, mas acaba que não é isso que acontece de forma efetiva [...]" (E2), limitando-se as organizações a manter um código de conduta. Nesse sentido, foi possível perceber grandes diferenças nas definições de ética das organizações investigadas, o que abre caminho para muitas interpretações e, possivelmente, comportamentos diferenciados.

Procedendo à investigação dos documentos das empresas, foi possível perceber que muitos dos seus extensos códigos de ética não refletem questões ambientais ou humanas, mas apenas aspectos de comportamento corporativo como exercer a profissão com zelo ou manter sigilo sobre o que souber em função de sua atividade profissional.

Isto pode trazer algumas implicações graves. Afinal, se o código de ética tem um escopo estrito, a empresa pode, no campo da retórica, apresentar comportamentos pouco construtivos socialmente ou pouco sustentáveis sem deixar de apresentar uma "conduta ética", ou seja, sem violar o seu próprio código.

A empresa do entrevistado 13, por exemplo, apresentou o mais completo código de ética e conduta das organizações investigadas, quando comparado com os ideais do movimento das Lideranças Globalmente Responsáveis, mas quando pedido por exemplos, o entrevistado não se lembrou de nenhum. Ainda segundo ele, a empresa sofre dificuldades, principalmente no quesito tempo, em países onde a prática de corrupção é muito elevada por privilegiar o processo correto. Pode-se perceber neste caso um grande esforço do departamento de comunicação organizacional na divulgação de ideais de RSE, restando saber se essas afirmações são amparadas por práticas empresariais.

Constatou-se até aqui que, para a maioria dos gestores entrevistados, o comportamento ético está restrito à presença de um código empresarial que trate do assunto, e não da capacidade de se experimentar esse comportamento pelos exemplos de ações cotidianas. Talvez por esse motivo alguns entrevistados são categóricos: "[...]a questão ética vem, mas normalmente é uma questão de conveniência" (E2). Para um deles, a ética "[...] é um aspecto que faz parte da conversa, agora qual é a sua aplicação, qual é a sua discussão, qual é a sua radicalização em favor do que é correto, isso não é percebido (E2)" na grande maioria das empresas.

\subsection{Engajamento ao longo das fronteiras organizacionais}

O quarto grupo de perguntas procurou avaliar quais procedimentos estratégicos formais e estruturais são tomados de forma a melhorar o ambiente organizacional com seus parceiros internos e externos. Nisso indaga também se o cuidado e a atenção às pessoas e ao ambiente são tão importantes quanto o desenvolvimento financeiro. Procurou-se avaliar ainda se o comprometimento com RSE/Sustentabilidade se mantém, mesmo que sejam necessárias mudanças na maneira como a empresa faz as atividades.

No que diz respeito ao relacionamento com os parceiros internos e externos, as empresas, segundo os entrevistados, apresentaram comportamentos diversos, embora poucas tenham sido as que apresentaram algum tipo de relacionamento com os fornecedores. Quanto à questão relativa ao comprometimento com RSE que envolva mudanças, nenhuma das empresas demonstrou flexibilidade para mudar suas práticas, negociando, por exemplo, com os concorrentes, caso necessário. 
Duas entre as 15 empresas apresentaram uma preocupação maior com as questões concernentes ao público interno. Para exemplificar isso, afirma que na passagem da crise mundial o presidente entrou em contato com todos por meio de um áudio conferência, onde disse: "[...] esse problema econômico-financeiro não é um problema da empresa". A organização passou pela crise sem perder receita e continuou apresentando crescimento, como confirma a análise dos balanços anuais.

Já no que diz respeito à valorização do tratamento com os parceiros externos, também somente duas apresentaram medidas mais significativas, tais como "[...] um programa de desenvolvimento de qualidade com os fornecedores" (E11) e um encontro anual, com premiação aos fornecedores que, por exemplo, não permitiram "pessoas sem carteira assinada" (E5). Há uma aparente confusão de obrigações legais e RSE. Algumas organizações afirmam ter regras para garantir condições mínimas de segurança aos funcionários. Entretanto, esse é um requisito mínimo expresso na lei brasileira.

De maneira geral "[...]as ações de meta são ações de aumento de faturamento da empresa e redução de despesas. Nada assim relativo a questões éticas não" (E2). Da mesma forma "[...] esse cumprimento de metas não está vinculado a ações de responsabilidade social ou a ações de satisfação interna. Estão vinculados ao aumento de receita e à diminuição das despesas e só" (E1).

Caso especial constitui o entrevistado 13. Afirma ele que, antes de fechar um negócio, é montado um plano de relacionamento com as partes interessadas. Cita o setor de bicombustíveis, onde a empresa, após a identificação dos principais stakeholders, definiu alguns aspectos a serem defendidos como uma "bandeira comum" com ONGs e parceiros.

Além de nenhum aspecto de preocupação com a RSE ter sido levantado nesse momento, a associação com ONGs no exemplo citado é digna de investigação, uma vez que a grande maioria daquelas empresas que praticam um discurso voltado para a questão ambiental não é a favor da implementação desse tipo de combustível, além de possuir um longo histórico de combate a muitas ações da empresa em questão.

Logo em seguida, diz o entrevistado que são formadas “[...] equipes de comunicação, de como você vai se comunicar com esse público, de como você vai interagir com a mídia, de que maneira você vai criar o ambiente correto" (E13) na propagação dessas atividades.

Embora em um primeiro momento essa frase possa não revelar nada de excepcional, a associação de "criação do ambiente correto" e "mídia" abre espaço para várias interpretações. Avaliando o contexto global em que a empresa está inserida, talvez possamos perceber maiores implicações. Vamos então avaliar algumas dessas questões emergidas no discurso do entrevistado:

O primeiro questionamento refere-se ao investimento pesado no setor de biocombustíveis. A implementação desse sistema é vista com muito receio por muitos pesquisadores, pois, para eles, aparenta ser um investimento lucrativo somente para as corporações envolvidas no processo. Alguns problemas podem decorrer do seu uso, como por exemplo: aumento das áreas devastadas para a implementação de monoculturas; no preço geral dos alimentos pela diminuição das áreas cultiváveis; incapacidade de determinar se isso significará uma redução no preço final do combustível para o consumidor; manutenção do rendimento dos motores em quilômetros por litro, fator inalterado desde a década de 1970.

Não é nossa intenção discorrer nesse trabalho sobre esse assunto, que por si só renderia várias outras pesquisas e estudos. Entretanto, é válido mencionar que medidas realmente sociorresponsáveis nesse sentido consistiriam, por exemplo, na implementação de veículos como o carro a água, o carro elétrico, ou mesmo o carro a ar. Neste contexto, vale ressaltar que existe uma série de modelos perfeitamente funcionais e de baixo custo de produção, inventados desde a década de 1960 aos dias atuais, ecologicamente corretos, conhecidos e mesmo com direitos de fabricação adquiridos pelo governo brasileiro em alguns casos. Uma organização cujo interesse aliasse o bemestar social com oportunidade de negócios poderia explorar profundamente essas novas formas de energia. 
A segunda questão trata do precário investimento da empresa em energias renováveis. Embora tenha sido uma das pioneiras no setor, ainda na década de 1990, a investir na pesquisa de novas fontes de energia, e ser uma empresa que investe significativamente na comunicação de práticas socialmente responsáveis, uma análise dos documentos organizacionais revela que ainda hoje a empresa investe mais de $90 \%$ da sua verba em pesquisa nos estudos de combustíveis tradicionais. Caso se acrescente aqui a pesquisa com biodiesel, o investimento em outras áreas é ainda bem menor. Vale apontar que essa empresa havia estabelecido, ainda na década de 1990, o compromisso de investir de maneira pesada nas pesquisas em novas formas de energia, tendo chegado mesmo a mudar o seu nome e slogan em função disso. Estima-se que somente nessa campanha de marketing tenham sido gastos mais de duzentos milhões de dólares.

Como terceiro questionamento, temos o envolvimento da organização investigada em um grave acidente ambiental. Além de não ter mostrado possuir os mecanismos corretos para o controle do problema, a empresa comprou direitos de um dos buscadores da internet para que, quando colocadas as palavras-chave do acidente, os primeiros resultados direcionassem para as páginas da organização, o que sugere uma tentativa de minimizar os impactos do acidente na mídia. Desta forma, levanta suspeita a fala do entrevistado (E13), quando este disse que a empresa privilegia a ação correta em outros países do mundo, por mais que isso atrase sua agenda em questões anteriores.

Como último questionamento, mostra-se a interferência desta mesma organização em várias crises que aconteceram com alguns países do Oriente Médio há mais de meio século, ora apoiando ditaduras, ora praticando sanções econômicas. Todas essas medidas têm ajudado a promover o aumento da miséria em larga escala e uma série de desestruturações políticas e sociais no local.

Tendo analisado essas questões, podemos perceber aqui que o comportamento da organização pode sugerir a existência de práticas de greenwash. Essa organização possuía uma forte imagem de RSE, porém, com o acidente ambiental apresentou uma queda elevada no preço de suas ações e um aumento de mais $70 \%$ no seu seguro. Além de prejudicar sua imagem, revelou uma série de outros escândalos que até então não haviam repercutido na mídia, o que trouxe uma série de reflexões na comunidade internacional.

Voltando novamente o foco para todas as quinze empresas estudadas neste trabalho, as entrevistas sugeriram uma possível prática de greenwash não somente na empresa acima tratada como em outras organizações.

\subsection{Operacionalização da RSE}

A nova série de perguntas procurou avaliar a operacionalização da RSE. Para isso investigou como a prática da RSE/Sustentabilidade está presente ao longo da cadeia de produtos/serviços da organização e se ela possui uma linguagem específica necessária a cada grupo envolvido. Procurou observar também como essas práticas estão ligadas às atividades do dia-a-dia das pessoas, averiguando se na descrição de cargos existe um conjunto mínimo de práticas socialmente responsáveis.

Neste momento da entrevista, já pode ser percebido certo distanciamento entre discurso e prática em várias organizações, estando às medidas de marketing muito perceptíveis nas respostas, ou na incapacidade de fornecê-las. Começam também a se delinear alguns perfis de como tem sido as práticas de RSE para as diversas empresas pesquisadas.

Mais uma vez, as empresas de médio porte aparentam ser as que mais desenvolveram mecanismos de gestão socialmente responsáveis entre as organizações investigadas. A adaptação da linguagem a cada segmento aparenta ser uma constante preocupação, relatando-se também planos e ações específicas para manter um bom ambiente de trabalho, tais como os "cafés com o gerente" e fóruns de discussão para que as pessoas tenham voz e, além de conversar abertamente com seus superiores, pudessem melhorar o ambiente interno (E7). 
A maioria das organizações de grande porte apresentou "[...] uma linguagem única para toda empresa" (E14), sendo esse um fator de grande dificuldade e de contradições. Um deles, por exemplo, afirma que a "[...] responsabilidade social está na estratégia da comunicação como um todo" (E10), mas que a empresa "[...] não trata especificamente da responsabilidade social" (E10). Assim sendo, como os colaboradores podem perceber uma efetiva responsabilidade social no seu dia-a-dia sem tratar com ela? Se inferirmos que a frase "[...] não trata especificamente da responsabilidade social" significa "[...] trata desse assunto de maneira geral", poderíamos sugerir que o entrevistado estava mencionando um fenômeno cultural. Todavia, essa suposição não foi amparada por nenhum exemplo na entrevista ou explícita nos documentos empresariais.

Isso era esperado de certa forma. Afinal, essa organização específica se encontra entre as dez mais poderosas empresas do mundo em 2009 e investe menos que $0,1 \%$ do seu faturamento anual em RSE, valor esse claramente insignificante frente à sua capacidade.

Forneceremos aqui mais alguns dados que parecem sugerir uma prática de irresponsabilidade social, ou greenwash, também por parte dessa organização. Embora ela conte com cerca de 20 mil colaboradores no Brasil, tendo sido contratados mais de 8 mil nos últimos 3 anos, é necessário analisar como tem sido seu comportamento no mundo.

Apesar de sua origem norte-americana, a empresa reduziu neste país o número de empregos de 300 mil em 2003 para 100 mil atualmente. Embora boa parte das demissões no seu país de origem tenha sido alegada por causa da crise internacional, a empresa apresentou, no momento máximo do problema financeiro, um crescimento de $12 \%$ em relação ao lucro do mesmo trimestre do ano anterior.

A empresa claramente adotou a prática de offshore, ou seja, adotou um modelo de realocação de processos de negócio para outro país, o que não nos cabe questionar. Entretanto, esse processo acarretou também uma diminuição considerável no salário global dos funcionários para que ocorresse a manutenção dos empregos, bem como redução de benefícios. A maior parte de sua receita vem hoje de mercados, tais como Brasil, Rússia, Índia e China, onde a exploração da mão de obra barata agrava as desigualdades sociais.

\subsection{Accountabillity de performance}

Finalmente, o último grupo de questões procurou avaliar como as práticas de RSE/Sustentabilidade são reconhecidas e recompensadas nas organizações entrevistadas. Averiguou também se os departamentos incluem metas específicas de responsabilidade social, recebendo os funcionários algum tipo de feedback para melhorarem seus comportamentos de RSE/Sustentabilidade.

Nessa altura da pesquisa, já se mostra possível observar que muito poucas empresas chegam, segundo seus entrevistados, até esse nível, seja por meio das evidências dos discursos, seja por intermédio dos documentos empresariais.

Entre as grandes organizações, apenas uma apresentou medidas que correspondem a práticas socialmente responsáveis. Como exemplo, citou um processo de redução de energia "[...] não muito pela conta, mas mais pela conscientização das pessoas" (E11).

Porém, a maioria dos entrevistados mostrou-se pessimista quanto ao estabelecimento de metas de RSE ou mostraram inconsistências entre seu discurso e sua prática. Um dos entrevistados revelou algo muito interessante que pode ajudar a compreender parte do discurso encontrado nas empresas. Inicialmente ele afirma: “[...] eu não tenho permissão para divulgar nenhuma informação em nome da empresa, então imagino que fique confidencial tanto o nome da empresa, quanto do entrevistado". Nada de excepcional até aí, porém mais a frente ele completa que "[...] todo tipo de informação tem que ser passada por um departamento" antes de sair da empresa, de modo que ela “[...] tem que ser conversada antes" (E10) para que, além de não vazarem informações estratégicas, não se afete a imagem pública organizacional. 


\section{CONSIDERAÇÕES FINAIS}

Como apontado pela teoria, as empresas entrevistadas encontram-se em diversos estágios da implementação da RSE como efetiva prática organizacional. Da mesma forma, foi possível perceber que o papel desempenhado pelos líderes é fundamental na disseminação de práticas socialmente responsáveis, colocando-as como processo estratégico dentro dos negócios, o que vai ao encontro com a literatura discutida.

Em todas as empresas de médio porte, pode-se perceber que as noções de uma efetiva prática de responsabilidade social são possíveis quando são originadas na cultura da empresa e propulsionadas pela imagem de seus líderes. De maneira geral, elas demonstraram ter sido capazes de criar certo envolvimento e motivação com seus funcionários e demais stakeholders, sem deixar de preservar o ambiente e perseguir lucros justos. Entretanto essa característica pode constituir uma coincidência da amostra escolhida para essa pesquisa.

Por outro lado, a maioria das empresas entrevistadas mostra sinais de apresentar um discurso ainda bem distante da prática. Isso pode ser verificado pela dificuldade de muitos entrevistados em fornecer exemplos conclusivos nas suas respostas. Mesmo quando davam exemplos, muitos não apresentavam um conhecimento ou engajamento com efetivas práticas de responsabilidade social, de acordo com os 7Cs de Maak (2008).

Embora muitas respostas dos entrevistados sejam elaboradas e aparentem contemplar vários aspectos de RSE, quando submetidas a uma análise mais detalhada de conteúdo, dos documentos empresariais ou da conjuntura mundial de suas organizações, podem revelar exatamente o oposto. Quando um dos entrevistados afirmou a necessidade de toda informação ser discutida em um departamento em especial isso levanta ainda mais questões sobre a real fundamentação de muitas respostas. Até que ponto elas podem ter refletido a realidade não sendo apenas um "discurso politicamente correto"?

Mesmo problema revela a questão da ética, conceito polissêmico onde predominam aspectos puramente concernentes aos deveres para com a organização e dificulta a averiguação de possíveis desvios de conduta. Isso foi perceptível, não só nas entrevistas, mas pela análise dos códigos de ética das organizações estudadas. Neles, o conceito de ética pareceu refletir características diferentes, predominando aspectos puramente concernentes aos deveres para com a organização, o que pode sugerir a necessidade de uma reformulação e atualização em muitas organizações para as novas necessidades do século XXI. Um código que tenha conceitos de comum acordo sobre a ética pode facilitar também a comunicação e a averiguação de possíveis desvios de conduta.

Nesse sentido, parece haver uma distância muito grande entre discurso e prática na maioria das empresas investigadas, bem como um parco entendimento do que seriam práticas globalmente responsáveis, existindo até mesmo uma falta de interesse no assunto.

Neste contexto, a liderança desempenha papel central e decisivo no processo de mudança organizacional e na promoção de práticas socialmente responsáveis; por isso, a compreensão do atual quadro em que se encontram pode ajudar não somente a construir novas propostas curriculares, mas também melhorar as já existentes na educação de executivos, bem como ajudar na criação de uma nova concepção do ensino da administração no médio e longo prazo. Entretanto, é preciso que ocorra simultaneamente uma reformulação nos conceitos e valores ensinados nas escolas, que se ocupe sobre a formação de valores, da infância ao nível superior. Afinal, é difícil exigir das lideranças organizacionais comportamentos humanos, inclusivos e fraternos quando a sociedade como um todo valoriza a exploração e a competição.

\section{REFERÊNCIAS}

Aglieri, L.; Borinelli, B.(2001) Responsabilidade social nas grandes empresas da região de Londrina. In: Encontro da ANPAD, 25. Campinas, Anais eletrônicos. 
Azevedo, A. L.(2006) Indicadores de sustentabilidade empresarial no Brasil: uma avaliação do Relatório CEBDS. Revista Iberoamericana de Economía Ecológica. 5, 75-93.

Bennis, W.G. (2002) A nova liderança e gestão de pessoas. (pg. 31-46). São Paulo. HSM Editora e Publifolha.

Blake, R.R. Mouton, J.S. (1989) O grid gerencial. São Paulo: Pioneira, 15, 329.

Bruno, K. (1992) The Greenpeace Guide to Greenwash. Greenpeace International.

Burns, J. M. (1978) Leadership. Harper \& Row, New York.

Carvalho Neto, A., Andrade, J.O. (2009) Responsabilidade social empresarial: quando as parcerias público-privada podem fazer a diferença. In: Silva, J.O., Stadtlober, C. de S. (Org.). Gestão social, solidariedade e cidadania. (1 ed.) Passo Fundo / Porto Alegre - RS: Imed.

Carvalho Neto, A., Furtado, R.A.(2007) A interface entre a responsabilidade social empresarial, as relações de trabalho e a gestão de pessoas: novas e velhas questões. EnGPR, 1. Natal. Anais eletrônicos.

Doh, J., Stumpf, S. (2005) Towards a framework of responsible leadership and governance. In: Doh, J., Stumpf, S. Handbook of Responsible Leadership and Governance in Global Business. London: Edward Elgar.

EFMD - European Foundation for Management Development. (2006) The Globally Responsible Leadership Initiative: taking action to ensure the next generation of business leaders act in a globally responsible way. Brussels: Martine Torfs.

Eisenhardt, K.M. (1989) Building theories from case study research. Standford University. Academy of Management Review (n. 4). Standford, 14.

Elkington, J. (1998) Cannibals with forks: the triple bottom line of 21st century business. Gabriola Island: New Society Publishers.

Graeff, C. (1983) The situational leadership theory: a critical review. Academy of Management Journal, 8, 285-91.

Hardjono, T., Klein, P. de. (2004) Introduction on the European Corporate Sustainability Framework (ECSF). Journal of Business Ethics, 55, 99-113.

Maak, T. (2008) Undivided corporate responsibility. Journal of Business Ethics, 82.

Maak, T., Pless, N.M. (2006) Responsible leadership in a stakeholder society. A relational perspective. Journal of Business Ethics, 66, 99-115.

Melo Neto, F. P., Froes, C. Q. (2001) Gestão da responsabilidade social corporativa: o caso brasileiro. Rio de Janeiro: Qualitymark Editora.

Molica, D. G., Carvalho Neto, A., Gonçalves, P. (2008) Responsabilidade social empresarial: oportunidades perdidas para trabalhadores e empregadores. Revista Brasileira de Gestão de Negócios (São Paulo), 10, 215-233. 
Pfeffer, J. (1977) The ambiguity of leadership. Academy of Management Review, January, 104-112.

Quinn, L., D'amato, A. (2008) Globally responsible leadership: a leading edge conversation. Center for Creative Leadership.

Sant'anna, A. S., Vaz, S. L., Nelson, R. E., Campos, M. S., Leonel, J. N. (2009) Liderança: uma análise sob a perspectiva de acadêmicos brasileiros e norte-americanos. In: Enanpad, 33. São Paulo.

Schein E.(1992) Organizational culture and leadership. (2ed.) Jossey-Bass: São Francisco.

Schwartz, M.S., Carroll, A.B .(2003) Corporate social responsibility: a three-domain approach. Business ethics quarterly, 13(4), 503-530.

Seters, D. A., Field, R. H. G. (1990) Leadership. Journal of Organizational Change Management, 3(3), 29.

Szekely, F., Knirsch, M. (2005) Responsible leadership and corporate social responsibility: metrics for sustainable performance, European Management Journal, 23(6), 628-47.

Tanure, B., Evans, P., Pucik, V.(2006) A gestão de pessoas no. Brasil: virtudes e pecados capitais. Rio de Janeiro: Campus.

Tenório, F. G. (2004) Responsabilidade social empresarial. Rio de Janeiro: Editora FGV, p. 166186.

Triviños, A. N. S.(1987) Introdução à pesquisa em ciências sociais: a pesquisa qualitativa em educação; o positivismo, a fenomenologia, o marxismo. São Paulo: Atlas.

Unesco.(2005) Década das Nações Unidas para o Desenvolvimento Sustentável 2005-2014. Brasília: Unesco.

Yin, R.K. (2003) Case study research: design and methods. (3. ed.) Thousand Oaks: Sage, 181.

Yukl, G. (2009) Leadership in organizations. (7. ed.) Upper Saddle River: Pearson Education Inc, 644.

Data da submissão: 30/09/2011

Data da publicação: 30/04/2013 